\title{
O ESTUDANTE E SUA RELAÇÃO COM AS TECNOLOGIAS DIGITAIS: Representações em sua aprendizagem ${ }^{1}$
}

Dirce Aparecida Foletto de Moraes ${ }^{2}$ Claudia Maria de Lima ${ }^{3}$

\section{INTRODUÇÃO}

A compreensão sobre os processos cognitivos do sujeito jovem adulto requer, inicialmente, o entendimento sobre os aspectos sociais e culturais do contexto em que esse sujeito está situado, e não somente aqueles relacionados ao indivíduo em si, de forma isolada. O ser humano é um sujeito histórico e, por isso, "[...] fica incompleto enfocar somente o relacionamento do desenvolvimento individual e da interação social sem se preocupar com a atividade cultural na qual as ações pessoais e interpessoais acontecem" (ROGOFF, 1998, p. 125). Assim, deve-se considerar o meio social e cultural, as práticas e as experiências vivenciadas, tanto individuais quanto comunitárias, bem como a maneira como as tecnologias participam da sua vida e de suas atividades.

Cole e Engestrõm (1993) defendem que a estrutura básica da cognição humana resulta da mediação das tecnologias, não apenas pela introdução destas em certo contexto, mas pelas diferentes práticas e formas de atividades que possibilitam no meio social e cultural.

Assim, por serem mediadoras da mente humana, as tecnologias potencializam as funções cognitivas que resultam em experiências, conduzem à novas práticas e à construção de novos cenários. Para Zille (2012, p. 104), muito mais do que ser um elemento auxiliar da cognição, as tecnologias promovem mudanças cognitivas e possibilitam o entendimento sobre "[...] o mundo de forma mais imediata por disponibilizar, de forma mais direta, informações já processadas [...] que podem potencializar o surgimento de novas modalidades de representações, significados e conhecimentos".

\footnotetext{
${ }^{1}$ Pesquisa financiada pelo Programa de Apoio a Capacitação Docente das Instituições Públicas de Ensino Superior do Paraná - Doutorado (Acordo Capes/Fundação Araucária). Chamada Pública nº 13/2014

${ }^{2}$ Doutora em Educação pela Universidade Estadual Paulista, Presidente Prudente (UNESP). Docente do Departamento de Educação da Universidade Estadual de Londrina - UEL. dircemoraes@uel.br

3 Doutora em Educação. Docente do programa de Pós-graduação em Educação da Unesp/Presidente Prudente. claudiamarialima@uol.com.br
} 
No contexto da sociedade do início do século XXI, a incorporação das tecnologias digitais tem ampliado-se, principalmente entre o público jovem, e tornado-se cada dia mais presente em suas vidas, servindo para a concretização de diferentes ações e para a constituição de novos significados em vários aspectos do contexto atual. Assim, o conjunto de práticas de uso e a interrelação entre os jovens com esses dispositivos têm favorecido o surgimento de um novo cenário social e cultural que parece desencadear a ampliação dos processos cognitivos desse sujeito.

As diferentes e intensas práticas de uso de certas tecnologias digitais como mediadoras e auxiliares das atividades cotidianas vêm transformando-as em instrumentos culturais capazes de provocar mudanças nas relações humanas e nas atividades, trazendo consigo representações não só na vida cotidiana, mas, também, no que se refere às formas e possibilidades de aprendizagem acadêmica.

Diante desse cenário, este estudo buscou investigar as representações que o estudante jovem adulto tem sobre as tecnologias digitais em sua aprendizagem a partir das apropriações e da interrelação estabelecidas.

\section{PROCESSOS COGNITIVOS DO JOVEM ADULTO E SUA RELAÇÃO COM AS TECNOLOGIAS: POSSIBILIDADES PARA A APRENDIZAGEM}

As transformações sociais, culturais e tecnológicas têm uma contribuição importante na aprendizagem e no processo cognitivo do jovem adulto, pois, além de mediar o pensamento e o funcionamento mental, as tecnologias e os símbolos de um contexto irão trazer desafios intelectuais ao proporcionar novos e diferentes ambientes de aprendizagem.

A natureza dos processos cognitivos do adulto não é igual em todos os lugares, pois diferencia-se de acordo com as mudanças históricas e culturais que ocorrerem em uma determinada sociedade. Para Lemme (1995, p. 151), as atividades cognitivas podem ser alteradas no percurso histórico, pois “[...] mudanças no contexto não apresentam apenas conteúdo novo (novas ideias, conhecimentos), mas também novas formas de atividade cognitiva".

Para tanto, importa ressaltar que em cada época histórica as ações humanas coletivas irão transformar o meio e o processo mental constituídos a partir das atividades. Nesse sentido, vale destacar que “[...] mente, cognição, memória etc. são entendidas, não como atributos ou propriedades do indivíduo, mas como funções que podem ser executadas intermentalmente ou intramentalmente" (WERTSCH; TULVISTE, 2013, p. 64) com a participação do sujeito nas 
práticas da sua cultura, as quais envolvem o uso de tecnologias para diferentes fins, os quais geram novas práticas.

$\mathrm{Na}$ atualidade, as tecnologias digitais se tornaram "instituições" primárias da cultura entre pares e passaram a desempenhar um papel importante na vida dos jovens adultos, que se apropriaram delas em suas vidas cotidianas de diferentes formas e para diversos fins. Esse é um indicador de mudança nos aspectos sociais e culturais contemporâneos, pois tanto as atividades quanto as formas de socialização foram alteradas e deram espaço para outras linguagens e para a produção de novos sentidos a partir de uma cultura compartilhada, denominada por Lévy (1999) como cibercultura.

O princípio da cibercultura está na inter-relação entre as tecnologias e a cultura e, segundo o mesmo autor, pode ser caracterizado pela interconexão, pelas comunidades virtuais e pela inteligência coletiva. A cibercultura é sustentada, de forma preponderante, por um grupo formado pela juventude metropolitana escolarizada que se reúne a partir de "[...] centros de interesses comuns, sobre o jogo, o compartilhamento do saber, sobre a aprendizagem cooperativa, sobre processos abertos de colaboração" (LÉVY, 1999, p. 132). Com isso, a cada dia as pessoas vão imergindo em um novo oceano de comunicação e de produção de informação.

Em nosso cotidiano vemos as pessoas habitando o mundo virtual, constituindo comunidades, relações com o outro e com o mundo, e formas variadas de comunicação. Esse mundo se tornou instantâneo, imediato, pois os sujeitos podem se comunicar e interagir de onde estão com seus pares e com pessoas desconhecidas em várias partes do planeta e de diversas formas, rompendo com as comunidades locais constituídas somente pela condição da presença física e a ideia da comunicação unilateral de um para um para dar espaço a diversos formatos de diálogo.

Santaella (2010) expressa que um ganho em relação às outras mídias é que nas digitais o sujeito precisa lidar com o excesso de informações que não são lineares, e isso traz mudanças na forma de aprender, diferentes dos formatos anteriores. E é nesse contexto que o jovem adulto vive e convive desde a infância. A socialização e a familiaridade com as tecnologias digitais e os diferentes recursos que oferecem lhe permitiram desenvolver diversas práticas de uso e apropriações que se consolidam em uma relação de proximidade e necessidade desses instrumentos em sua vida, as quais estão potencializando-se como uma " [...] multifuncionalidade cognitiva cujas consequências sobre a aprendizagem deverão ser investigadas de maneira detalhada" (MONEREO; POZO, 2010, p. 103-104). 
É pelas tecnologias que esses jovens realizam diferentes atividades e vivenciam experiências distintas promovidas por eles e por seus pares para atender as necessidades educativas e para aprender. Assim, as apropriações e a inter-relação que o jovem adulto vem estabelecendo com as tecnologias digitais conduzem a novas práticas sociais e culturais, e trazem novos significados e representações não só na vida cotidiana, mas, também, na aprendizagem desses sujeitos.

Bonk e Kim (1998) destacam que as invenções modernas são oportunidades adicionais que estimulam e desafiam os jovens adultos no meio sociocultural e oferecem oportunidades adicionais aos contextos do ensino superior. No entanto, indicam que é necessário entender como essas tecnologias estão interligados e como a aprendizagem se organiza a partir de seu uso.

\section{CAMINHOS DA PESQUISA}

O presente estudo, recorte da pesquisa de doutoramento de uma das autoras, tem como objetivo geral investigar as representações dos discentes ingressantes na universidade sobre as tecnologias digitais em sua aprendizagem a partir das apropriações e da inter-relação estabelecidas. Como objetivos específicos, buscou identificar as percepções dos estudantes sobre sua aprendizagem a partir da inter-relação com as tecnologias digitais; perceber as compreensões dos estudantes em relação ao uso das tecnologias para aprender; e identificar as representações das tecnologias na vida como estudante.

Em relação aos objetivos propostos, este estudo tem como delineamento a pesquisa qualitativa, de caráter exploratório-explicativo. O público alvo foi constituído por 41 estudantes ingressantes em um curso de formação de professores de uma universidade pública do interior do Paraná. Esses estudantes fazem parte de uma turma do período noturno, composta por 41 alunos, dos quais 55,6\% têm, no máximo, 20 anos, 36,1\% têm entre 21 e 30 anos e 8,3\% têm de 31 a 40 anos.

Os dados foram coletados por meio de um questionário on line, composto por 10 questões abertas e fechadas. Concorda-se com Gil (2012, p. 121) quando este afirma que "o questionário consiste basicamente em traduzir os objetivos da pesquisa em questões específicas [...]”. O questionário foi elaborado em formato digital e encaminhado aos estudantes via email da turma, podendo ser respondido em sala de aula ou em outro momento, e foi elaborado e aplicado respeitando o objetivo deste estudo e suas variáveis. Do total de 41 estudantes, obteve-se o retorno de 36 respondentes. 
Para a realização da análise e a interpretação dos dados, foi utilizada a Análise de Conteúdo proposta por Bardin (1977), que consiste, segundo a autora, em tratar as informações seguindo um roteiro composto por três fases, sendo elas: a pré-análise, a exploração do material e a categorização.

Os dados foram codificados a partir do objetivo e dos indicadores que orientaram a elaboração do questionário. A categorização foi organizada a posteriori, pois, como o objetivo era investigar as representações, considerou-se que as categorias deveriam imergir das respostas dos sujeitos, e não de um quadro preestabelecido. As categorias foram eleitas no sentido de serem capazes de produzir inferências sobre as representações das tecnologias digitais na aprendizagem a partir da inter-relação que o jovem estabelece com tais dispositivos. Os dados foram analisados tendo como base a teoria da Cognição Distribuída, a qual entende que o processo cognitivo está associado ao processo sócio-histórico e, dessa forma, rompe a ideia de que a pessoa aprende sozinha e consolida a compreensão de que essa é uma construção social que se dá por meio da mediação e das interações entre humanos e não-humanos.

\section{O JOVEM ADULTO E AS REPRESENTAÇÕES SOBRE A INTER-RELAÇÃO COM AS TECNOLOGIAS DIGITAIS EM SUA APRENDIZAGEM}

Para compreender as representações que o jovem estudante adulto tem sobre a relação com as tecnologias digitais em sua aprendizagem, as questões foram organizadas em bloco a partir do direcionamento dos objetivos. Assim, na tentativa de identificar as percepções dos estudantes sobre sua aprendizagem a partir da inter-relação com as tecnologias digitais, perguntou-se aos estudantes se eles consideram a inter-relação com as tecnologias favorável, ou não, à aprendizagem. As respostas indicaram que todos os estudantes, 100\%, concordam que é, sim, favorável. Na sequência, questionou-se as razões atribuídas pelos jovens para aprender pelas tecnologias. As respostas encaminharam para a constatação de três categorias: fonte de informação, $68 \%$, espaço cooperativo, $24 \%$, e extensão da sala de aula, $8 \%$. Os dados se referem ao número de argumentos, e não de participantes.

As tecnologias como fonte de informação $(68 \%)$ foi a categoria eleita com maior frequência, pois elas são entendidas como recursos que oferecem diversos sites de pesquisa, como acesso à informação de que necessitam para aprender de forma rápida e fácil, o auxílio na resolução de problemas e como complemento da aprendizagem. Dentre os mais utilizados, destacam-se: artigos acadêmicos, videoaulas, sites de pesquisa e filmes. Os dados dessa categoria deixam explícito que os sujeitos pesquisados confiam nas tecnologias para aprender porque estas se constituem como 
espaço potencialmente ativo disponível às suas necessidades, porém, de forma limitada ao consumo daquilo que encontram.

Com $24 \%$ de frequência, a categoria espaço educativo evidencia que é possível aprender pelas tecnologias porque estas são espaços cooperativos nos quais os alunos podem interagir, trocar informação, aprender com o outro, compartilhar, fazer grupos de estudo, atividades online; além de ser uma possibilidade para o professor ensinar. Os dados presentes nessa categoria apresentam indícios de que alguns estudantes já percebem as tecnologias como ferramenta que vai além de uma fonte rica de informações e que pode oferecer muito mais aos jovens do que aquilo que encontram em sala de aula.

Com $12 \%$ de frequência, a categoria extensão da sala de aula se refere à capacidade de pesquisar, estudar e aprender a qualquer hora e em qualquer lugar, da maneira como cada um achar melhor, além de ser uma ampliação das condições de aprendizagem. Os dados apresentados nessa categoria indicam que os jovens confiam nas tecnologias para consumir conteúdos e dão indícios de uso para compartilhar e aprender, mesmo que isso ainda não seja uma prática muito constante.

Nesse bloco de questões é possível perceber que os estudantes já fazem uso das tecnologias para algumas atividades acadêmicas e que confiam nas tecnologias digitais para aprender. No entanto, necessitam de orientação e direcionamento para que possam aproveitá-las em seus processos formativos de forma que ultrapasse o uso para consumir.

Mamede-Neves e Duarte (2008, p. 785) explicam que, como “[...] reservatório de informações, como uma biblioteca babilônica de fácil acesso, as tecnologias digitais e a internet certamente prestarão um importante serviço à escola, mas não serão aproveitadas no que de melhor têm a oferecer $[\ldots]$ ”. Portanto, é preciso aproveitar ao máximo as potencialidades que elas oferecem para que o aluno possa explorar seu potencial e vivenciar experiências educativas.

Salomon, Perkins e Globerson (1991) expressam que os processos cognitivos podem ser favorecidos a partir do envolvimento do estudante e da parceria estabelecida com alguma tecnologia em situações de aprendizagem. No entanto, também destacam que não é no uso de qualquer ferramenta ou em qualquer situação que isso vai ocorrer, mas somente aquelas que permitem a realização de novas tarefas e diferentes operações cognitivas permitirão esse favorecimento.

A busca pelo entendimento das compreensões dos estudantes em relação ao uso desses dispositivos para aprender encaminhou ao questionamento sobre a relação às suas percepções sobre diferenças nas formas de aprender pelas tecnologias digitais e sem elas. 
Os resultados indicam que a maioria dos estudantes, composta por 91,7\%, considera que há diferença, e 8,3\% considera que não há diferença. Para o primeiro grupo, isso decorre da diversidade de possibilidades ofertadas pelas tecnologias digitais. Segundo os participantes da pesquisa, esses dispositivos permitem uma visão mais ampla do conceito e oferecem apoio para realizar trabalhos e pesquisas, diversas opções e formas de aprender, além de respostas mais rápidas às necessidades e informações que facilitam a aprendizagem. Os jovens consideram, também, que há mudança e diversidade de recursos, o que ajuda na aprendizagem. A seguir, alguns excertos exemplificam:

Quando aprendemos algo pelas tecnologias digitais vemos que as informações são sempre diversas, e que se tem várias opiniões diferentemente da que você encontra em sala, onde temos uma opinião sendo imposta a do docente (A05).

Em minha opinião, sem as tecnologias digitais você consegue se distrair mais fácil e ter mais dificuldade para expressar o seu conhecimento.Já com as tecnologias digitais você consegue pesquisar vários assuntos, você se concentra mais na atividade, você pode buscar filmes,vídeos sobre a matéria a ser estudada. Você consegue ver a opinião de várias pessoas sobre um determinado assunto (A23).

Diante dos dados apresentados nessa questão, não há como negar que a parceria estabelecida com as tecnologias acarreta significados e ocasiona mudanças nas formas de aprender dos jovens adultos. Isso leva a inferir que mesmo que a instituição educativa ainda não tenha feito uso do potencial das tecnologias para vivenciar experiências de aprendizagem, os jovens, por conta própria, vêm fazendo isso em paralelo e à sua maneira. Isso reforça a ideia de uma forma diferente de aprendizagem em meio a esse grupo.

Para Salomon (1992), nossa mente é afetada pelas tecnologias tanto por meio das experiências que decorrem das práticas de uso como pela representação cultural de tais ferramentas na sociedade. O autor expressa que o potencial das tecnologias "reside na sua capacidade de redefinir e reestruturar fundamentalmente o que fazemos, como fazemos e quando o fazemos [...]" (SALOMON, 1992, p. 149). Monereo e Pozo (2010, p. 110) corroboram expressando que a “[...] pluralidade e o uso integrado de múltiplos códigos tornam possível um conhecimento integrado e multimídia que parece ser o suporte ideal para um pensamento complexo".

O grupo que considera que não há diferença entre aprender pelas tecnologias, $8,3 \%$ dos jovens, entende que a aprendizagem não depende de tais dispositivos e considerara que a única função destes é otimizar o tempo. A seguir, alguns excertos exemplificam: 
Embora o aprendizado com os meios digitais seja mais otimizado, aprender sem eles ainda faz parte da nossa vida, e a troca de experiências favorece a diferença (A02).

Não considero porque para mim funciona, mas pode ser que para outras pessoas não funcione e isso não quer dizer que porque eu aprendo com a tecnologia me ajudando que outras pessoas aprendem menos porque não as utilizam (A33).

Também questionou-se se os alunos costumam utilizar, ou se já utilizaram, alguma ferramenta de compartilhamento, rede social ou outro canal de comunicação pela internet para estudar ou aprender. Como resposta, obteve-se $88,9 \%$ afirmando que sim e 11,1\% afirmando que não.

Para o grupo que respondeu sim, a categoria eleita foi "atende as diferentes formas de aprender". Esse grupo considera que isso acontece porque a diversidade de ferramentas e de conteúdos possibilita maior compreensão, concentração e ampliação do objeto de estudo. Assim, quando o aluno utiliza uma ou outra ferramenta, vai percebendo como e se esta atende mais ou menos às suas particularidades; diante disso, ele opta por caminhos que melhor conduzem à aprendizagem. Esse é um processo que se diferencia da prática da sala de aula, a qual muitas vezes restringe a aprendizagem a um único formato e a uma única ferramenta, desconsiderando a diversidade existente entre os sujeitos.

Para os estudantes que afirmaram nunca utilizar tais ferramentas para estudar ou aprender $(11,1 \%)$, a categoria eleita foi a "pouca utilidade". Tais dados revelam que esses estudantes encontram segurança no formato linear de aprender e que não depositam total confiança nas tecnologias e nas ferramentas de compartilhamento para este fim, seja por desconhecimento, seja porque consideram que as tecnologias servem para o lazer, e não para aprender. Ainda entendem que estas não são favoráveis a todos e que a aprendizagem depende de cada aluno, e não do recurso utilizado. Sobre isso, supõe-se que, talvez, as práticas sociais vivenciadas com tais ferramentas não tenham sido suficientes para pensarem diferente, ou não tenham correspondido à sua forma de aprender.

Por outro lado, essa informação é muito relevante no sentido de permitir refletir sobre o papel das tecnologias em sala de aula, pois elas não podem ser entendidas como uma panaceia ou a “cura para todos os males" da educação, mas precisam ser apropriadas de forma crítica por todos os personagens do processo, para que, assim, possam cumprir com sua função pedagógica.

Coll e Monereo (2010, p. 76) entendem que tais ferramentas apresentam grande potencial enquanto mediadoras do processo educativo, dos conteúdos e das comunicações, no entanto, elas só 
atingem os propósitos se forem "[...] utilizadas por alunos e professores para planejar, regular e orientar as atividades próprias e alheias, introduzindo modificações importantes nos processos intra e interpsicológicos envolvidos no ensino e na aprendizagem”. Onrubia, Engel e Engel (2010, p. 223) corroboram alertando que consideram “[...] pouco provável que as novas ferramentas possam ter um valor pedagógico sem estratégias educacionais cuidadosamente previstas e professores adequadamente treinados".

Para o grupo que respondeu que já utilizou alguma ferramenta de compartilhamento, rede social ou outro canal de comunicação pela internet para estudar ou aprender com algum colega, solicitou-se que informassem o que a experiência representou. Diante das respostas, obteve-se a identificação de três categorias, que surgiram a partir do número de argumentos, e não de participantes. A primeira foi interação, com 57,90\%, a qual se refere à possibilidade de partilhar dúvidas, ideias e informações, além de favorecer a comunicação. Essa categoria demonstra, cada vez mais, que esse sujeito valoriza a participação e o trabalho em parceria, conforme defendem, também, vários autores (PEA, 1993; SALOMON, 1993).

Outra categoria foi o trabalho diferenciado, com 26,31\%, o qual representa algumas vantagens, como: ser interessante, atrativo, prático, fácil, diferente, trazer resultados positivos e imediatos. Para os estudantes, a experiência foi interessante, prática, fácil, diferente e trouxe resultados positivos, além de ter sido gratificante e importante para sua vida como estudante. Esse jovem busca o novo, o diferente e a experiência, e, quando isso ocorre, traz-lhe satisfação. A terceira categoria é a aprendizagem, com 15,80\% de frequência, que se refere à possibilidade que as tecnologias oferecem de atingir um conhecimento mais amplo sobre o tema.

Os dados indicam que os jovens se sentem satisfeitos ao usarem as tecnologias nas atividades acadêmicas da mesma maneira como ficam ao usar para outros fins em sua vida cotidiana. Além disso, eles passam a entender que a aprendizagem por esses meios é diferente da que acontece em sala de aula. Os dados evidenciam, ainda, que as práticas sociais vivenciadas pelos jovens com as tecnologias no meio sociocultural fornecem-lhes condições para selecionar as ferramentas favoráveis para as atividades acadêmicas.

Salomon (1997) explica que quando o aprender é entendido como "absorver conteúdos de forma passiva", o quadro negro e a televisão, então, são suficientes; quando a aprendizagem é entendida como a resposta aos estímulos externos, as tecnologias de instrução programada, então, corresponde; no entanto, quando o aprender é entendido como uma prática social construída, as 
tecnologias digitais, então, ganham espaço e notoriedade, e seu uso passa a fazer sentido em sala de aula.

Esses jovens também foram questionados sobre as práticas de uso dessas tecnologias/recursos em seus estudos. Os resultados indicam as seguintes categorias: pesquisar, com $61,11 \%$, assistir videoaulas, com 19,45\%, trocar informações, com 16,67\%, e compartilhar materiais, com $2,77 \%$. A frequência se refere ao número de argumentos, e não ao número de sujeitos. O que se pode perceber, diante desses dados, é que as práticas de uso são restritas, de certa forma, se comparadas ao grande potencial de uso que as tecnologias digitais oferecem.

Nesse levantamento pode-se perceber dados ambíguos, pois em certos momentos são evidenciadas práticas diferenciadas e representações significativas, como espaço de interação, de trocas e de colaboração. Porém, por outro lado, é possível verificar que o uso se dá meramente instrumental e de forma limitada. Tais dados encaminham para o entendimento de que os jovens indicam um possível valor pedagógico dessas ferramentas, mas isso não faz parte da sua realidade e de suas experiências; logo, precisam vivenciar mais e diferentes experiências no contexto pedagógico que promovam a seleção, a exploração, a análise, a síntese e a criação de informações, pois somente dessa forma terão a oportunidade de aproveitar ainda mais o que as tecnologias oferecem.

Assim, considera-se que o potencial das tecnologias não está naquilo que elas oferecem, nem na ferramenta em si, mas no tipo de atividade que os sujeitos irão desenvolver a partir do que elas oferecem (SALOMON; PERKINS; GLOBERSON, 1991; COLL; ONRUBIA, 2010).

Outro bloco de perguntas buscou identificar as representações do uso das tecnologias na vida do jovem como estudante. As categorias eleitas foram: ferramenta essencial, com 80,35\%, e ferramenta mediadora, com $19,65 \%$ de frequência. A frequência se refere à frequência dos argumentos, e não ao número de participantes.

A categoria "ferramenta essencial", mais representativa entre os estudantes, transforma as tecnologias em ferramentas potencialmente ativas para aprender. Os jovens atribuem confiança e credibilidade e designam a tais ferramentas funções muito importantes, como auxiliar em várias situações da vida acadêmica e na realização das atividades, de trabalho e de tarefas; também são essenciais porque proporcionam facilidade, agilidade, comodidade, eficiência, flexibilidade, praticidade, rapidez e economia de tempo. A seguir, alguns excertos que expressam essa categoria: 
Unir a internet com o aprendizado é algo muito bom, pois assim fazemos com que o aprendizado esteja com a gente o tempo todo, sempre que estivermos conectados a internet (A16).

Muitos professores ainda preferem usar o meio mais tradicional para a aprendizagem, não gostam muito de usar outros meios da tecnologia. Mas, hoje todos estão usando a tecnologia de alguma forma e em minha opinião isso é muito importante para os alunos conseguirem aprender a matéria. Precisamos usar muito a visão, o movimento. Porque isso é o que chama a nossa atenção e tenho certeza que é um meio mais fácil para aprender (A23).

Ferramenta mediadora é outra categoria que representa o uso das tecnologias na vida acadêmica desses jovens: esta indica que as tecnologias podem favorecer práticas e experiências que ajudam na compreensão dos conteúdos e a obtenção de mais informações sobre o que estão estudando, além de serem meios de aprendizagem, de comunicação, de pesquisa e de organização. Alguns excertos demonstram o que indica essa categoria:

Um meio para que meus aprendizados sejam completos (A05).

Representa um meio mais fácil e prático para que eu possa adquirir meus conhecimentos, me ajuda com meus trabalhos (A23).

Os dados apresentados nesse bloco indicam que, sendo uma ferramenta essencial ou mediadora, as tecnologias exercem um papel importante entre os jovens e, com isso, vão desvelando novas possibilidades no contexto educativo. Bonk e Kim (1998) expressam que as mudanças socioculturais decorrentes da inserção e do uso das tecnologias digitais promovem diferentes padrões de produção e novas formas de aprendizagem, como a colaboração, a interação, as trocas, a resolução de problemas, os desafios, entre outros, e reforçam que são aspectos que precisam ser considerados na universidade.

Outra questão buscou entender de que forma tais dispositivos ajudam ou podem ajudar nos estudos e nos trabalhos escolares. As respostas foram organizadas em três categorias: favorece a aprendizagem, com 47,27\% de frequência, auxilia na realização dos trabalhos, com 27,27\%, e favorece a comunicação e a interação, com $25,46 \%$ Esse resultado é referente ao número de argumentos, e não de participantes.

A categoria "favorece a aprendizagem" é entendida como uma forma de as tecnologias ajudarem os estudantes nos estudos e nos trabalhos escolares. Os jovens consideram que, além de facilitar seus estudos, as tecnologias são essenciais para o entendimento dos conceitos; outra prerrogativa é a de que auxiliam na descoberta de novas e variadas informações sobre o que estão 
aprendendo, servindo para complementar e aprofundar o conteúdo e, ainda, para ampliar o vocabulário. A seguir, alguns excertos:

Eles são as fontes que uso para complementar minha aprendizagem (A05).

São essenciais para o meu entendimento diante da matéria (A11).

São ferramentas que não dispenso, pois facilitam meus estudos e a forma de compreensão (A31).

A respeito da categoria "auxílio na realização dos trabalhos", para os jovens, as ferramentas disponíveis facilitam a produção dos trabalhos, ajudam nas pesquisas, oferecem muitas fontes de busca e tornam mais rápido e fácil o acesso aos conteúdos necessários para a realização dos trabalhos. Alguns excertos exemplificam:

Esses recursos muitas vezes me esclareceram dúvidas imediatas e facilitaram na produção de trabalhos, na descoberta de novos fatos (A01).

Ajudam contribuindo com conteúdos que muitas vezes não encontramos em bibliotecas ou em outros locais de pesquisa que não a internet, facilitando assim a busca pelo conhecimento (A14).

Já a categoria "favorece a comunicação e interação" evidencia que por meio das ferramentas os jovens compartilham trabalhos, interagem e se comunicam mais, bem como esclarecem dúvidas, ficam mais integrados e podem debater os assuntos da aula com os colegas em outros espaços e em momentos diversos. A seguir, alguns excertos exemplificam:

Melhoram a comunicação entre os alunos, e possibilita a busca por referenciais teóricos (A02).

No caso das pesquisas, nos trabalhos e essa é uma maneira de interagir melhor com os colegas, assim aprendendo mais junto com eles (A16).

Os dados apresentados nesse bloco encaminham ao entendimento de que, apesar da pouca experiência com o uso das tecnologias nas atividades acadêmicas, esses jovens indicam o valor pedagógico de tais ferramentas; no entanto, precisam vivenciar mais e diferentes experiências de práticas de uso no contexto pedagógico para que possam ampliar e entender as possibilidades que estas oferecem, como já mencionado.

Sobre isso, Coll e Monereo (2010, p. 89-90) consideram que é preciso priorizar “[...] os usos transformadores e inovadores das TIC [...] e usos que aproveitam por igual suas potencialidades de tecnologia de informação e comunicação [...]" na aprendizagem e no desenvolvimento do estudante. 


\section{CONSIDERAÇÕES FINAIS}

Os dados apresentados e analisados neste estudo apontam uma experiência pobre e limitada, na qual o uso se volta mais ao consumo de informações. No entanto, os jovens reconhecem e confiam nas tecnologias digitais como espaço potencialmente ativo para aprender e indicam a necessidade de vivenciar experiências significativas. A diversidade de informações, de ferramentas, de conteúdos e de possibilidades ofertadas pelos dispositivos permitem uma visão mais ampla dos conceitos e atendem às suas formas de aprender de maneira diferente do que vivenciam em sala de aula. Os estudantes consideram que as tecnologias também servem como apoio para a compreensão dos conteúdos, como fonte de informação e espaço cooperativo, proporcionam interação e trazem resultados imediatos e positivos, possibilitando novas descobertas, além de auxiliarem na realização das atividades e das tarefas.

Diante de tal confiabilidade, para esses jovens, as tecnologias são entendidas como ferramentas essenciais e mediadoras das aprendizagens. Coll e Onrubia (2010) explicam que, ao servirem como ferramentas mediadoras das relações entre conteúdos e tarefas de aprendizagem, as tecnologias são utilizadas pelos estudantes para procurar e selecionar conteúdos, acessar repositórios de conteúdos e de atividades com ou sem interatividade, explorar e analisar os conteúdos e realizar atividades e tarefas.

Para tanto, não basta apenas usar tais ferramentas para consumir conteúdo, mas o estudante precisa ter a oportunidade de vivenciar experiências didáticas que possibilitem aproveitar ao máximo as potencialidades que tais ferramentas oferecem, para que ele possa aprender ou ampliar as capacidades de explorar, analisar, sintetizar e problematizar e, assim, desenvolver-se.

Esse é um aspecto muito importante a ser considerado ao se pensar nas formas de ensino a serem desenvolvidas em sala de aula para atender às necessidades formativas desses sujeitos. Assim, pode-se considerar que "[...] não há dúvida de que a incorporação das TIC modifica e reestrutura as formas de pensar e de aprender e, consequentemente, deve-se modificar a forma de ensinar" (MONEREO e POZO, 2010, p. 104). 


\section{REFERÊNCIAS}

BARDIN, Laurence. Análise de conteúdo. Lisboa: Edições 70, 1977.

BONK, Curtis Jay; KIM, Kyung A. Extending sociocultural theory to adult learning. In: SMITH, M. Cecil; POURCHOT, Thomas. Adult learning and development: perspective from educational psychology. London: Lawrence Erlbaum Associates, Inc, 1998. p. $67-88$

COLL, C.; MAURI, T.; ONRUBIA, J.. A incorporação das tecnologias de informação e da comunicação na educação: do projeto técnico-pedagópgico às práticas de uso. In: COLL, Cesar; MONEREO, Carles (Orgs.). Psicologia da Educação virtual: aprender e ensinar com as tecnologias da informação e da comunicação. Porto Alegre: Artmed, 2010. p. 66-93.

COLL, Cesar; MONEREO, Carles (Orgs.). Psicologia da Educação virtual: aprender e ensinar com as tecnologias da informação e da comunicação. Porto Alegre: Artmed, 2010.

COLE, Michael; ENGESTRÖM, Yrjö. A cultural-historical approach to distributed cognition. In: SALOMON, G. Distributed cognitions: psychological and educational considerations. Cambridge: CUP, 1993. p. 01-46.

GIL, Antonio Carlos. Métodos e técnicas de pesquisa social. 6. ed. São Paulo: Atlas, 2012.

LÉVY, Pierre. Cibercultura. São Paulo: Editora 34, 1999.

LEMME, Barbara Hansen. Development in adulthood. Boston: Allyn \& Bacon, 1995.

MAMEDE-NEVES, Maria Apparecida Campos; DUARTE, Rosalia. O contexto dos novos recursos tecnológicos de informação e comunicação e a escola. Educ. Soc., Campinas, v. 29, n. 104 - Especial, p. 769-789, out. 2008. Disponível em: <http://www.scielo.br/pdf/es/v29n104/a0729104.pdf>. Acesso em: 28 set. 2017.

MONEREO, Carles; POZO, Juan Ignacio. O aluno em ambientes virtuais. In: COLL, Cesar; MONEREO, Carles (Orgs.). Psicologia da educação virtual: aprender e ensinar com as tecnologias da informação e da comunicação. Porto Alegre: Artmed, 2010. p. 97 135 .

ONRUBIA, Javier; ENGEL, Rosa Colomina; ENGEL, Ana. Os ambientes virtuais de aprendizagem baseados no trabalho em grupo e na aprendizagem colaborativa. In: COLL, C.; MONEREO, C. (Orgs.). Psicologia da educação virtual: aprender e ensinar com as tecnologias da informação e da comunicação. Porto Alegre: Artmed, 2010. p. 208-225.

PEA, Roy D. Practices of distributed intelligence and designs for education. In: SALOMON, G. Distributed cognitions: psychological and educational considerations. Cambridge: CUP, 1993. p. 47-87

ROGOFF, Barbara. Observando a atividade sociocultural em três planos: apropriação participatória, participação guiada e aprendizado. In: WERTSCH, James V. Estudos socioculturais da mente. Porto Alegre: Artmed, 1998. p. 122-136.

SALOMON, Gavriel. Las diversas influencias de la tecnología em el desarrollo de la mente. Journal: Infancia y Aprendizaje, v. 15, n. 58, jan. 1992, p. 143-159.

Distributed cognitions: psychological and educational considerations. Cambridge: CUP, 1993. p. 47-87.

Of mind and media: how culture's symbolic forms affect learning and thinking. Phi Delta Kappan, v. 78, n. 5, p. 375-380, 1997.

SALOMON, Gavriel; PERKINS, David; GLOBERSON, Tamar. Partners in cognition: extending human intelligence with intelligent technologies. Educational Researcher, v. 20, p. 2-9, 1991.

SANTAELLA, Lúcia. A aprendizagem ubíqua substitui a educação formal? Revista de Computação e Tecnologia, v. 2, n.1, p. 1722, 2010. Disponível em: <http://revistas.pucsp.br/index.php/ReCET/article/view/3852/2515>. Acesso em: 30 dez. 2017.

WERTSCH, James V.; TULVISTE, Peeter. L. S. Vygotsky e a psicologia evolutiva contemporânea. In: DANIELS, Harry (Org.). Uma introdução a Vygotsky. São Paulo: Edições Loyola, 2013. p. 61-82.

ZILLE, José Antônio Baêta. A intensificação do agenciamento nos games: do jogador ao jogador-criador. 2012. 159 f. Tese (Doutorado em Comunicação e Semiótica) - Programa de Estudos Pós-Graduados em Comunicação e Semiótica, Pontifícia Universidade Católica de São Paulo, São Paulo, 2012. 


\section{RESUMO}

Este estudo investiga as representações que o jovem estudante adulto tem sobre a relação com as tecnologias digitais em sua aprendizagem conceitual por meio de uma pesquisa exploratório-explicativa realizada com uma turma de jovens ingressantes em uma universidade pública do interior do Paraná. Os dados foram coletados por meio de um questionário online, tratados com apoio da Análise de Conteúdos e analisados com base na teoria da Cognição Distribuída. O estudo elucidou que os jovens confiam nas tecnologias como espaço potencialmente ativo para aprender pois oferecem uma diversidade de opções para tal e constituem-se como uma fonte de informações disponível às suas necessidades. Diante dessa confiabilidade, as tecnologias digitais são ferramentas essenciais e mediadoras das aprendizagens.

Palavras-chave: tecnologias digitais; estudante universitário; aprendizagem.

\section{THE STUDENT AND HIS RELATIONSHIP WHIT DIGITAL TECHNOLOGIES: REPRESENTATIONS IN HIS LEARNING}

\section{ABSTRACT}

This paper investigates the representations that the young adult student has about the relationship with digital technologies in their conceptual learning through an exploratory-explanatory research carried out with a group of young people entering a public university of the countryside of Paraná. Data were collected through an online questionnaire, processed with the support of the Content Analysis and analyzed based on the theory of the Distributed Cognition. The research elucidated that young people relies on technologies as a potentially active space to learn because they offer a variety of learning options and are a source of information available to their needs. Faced whit such reliability, digital technologies are essential tools and mediators of learning.

Keywords: digital technologies; university student; learning.

\section{ESTUDIANTE Y SU RELACIÓN CON LAS TECNOLOGÍAS DIGITALES: REPRESENTACIONES EN SU APRENDIZAJE}

\section{RESUMEN}

Este estudio investiga las representaciones que el jóven estudiante adulto tiene sobre la relación con las tecnologías digitales en su aprendizaje conceptual por medio de una investigación exploratorio-explicativa realizada con una clase de jóvenes ingresantes en una universidad pública del interior del Paraná. Los datos fueron recolectados a través de un cuestionario en línea, tratados con apoyo del Análisis de Contenidos y analizados con base en la teoría de la Cognición Distribuida. El estudio elucidó que los jóvenes confían en las tecnologías como espacio potencialmente activo para aprender, pues ofrecen una diversidad de opciones para ello y se constituyen como una fuente de información disponible a sus necesidades. Ante esta confiabilidad, las tecnologías digitales son herramientas esenciales y mediadoras de los aprendizajes.

Palabras clave: tecnologías digitales; estudiante Universitário; el aprendizaje. 